\title{
Blue Optical Observations of Narrow Bipolar Events by ASIM Suggest Corona Streamer Activity in Thunderstorms
}

Soler, S.; PérezInvernón, F. J.; GordilloVázquez, F. J.; Luque, A.; Li, D.; MalagónRomero, A.; Neubert, T.; Chanrion, O.; Reglero, V.; NavarroGonzalez, J.

Total number of authors:

14

Published in:

Journal of Geophysical Research: Atmospheres

Link to article, DOI:

10.1029/2020JD032708

Publication date:

2020

Document Version

Publisher's PDF, also known as Version of record

Link back to DTU Orbit

Citation $(A P A)$ :

Soler, S., PérezInvernón, F. J., GordilloVázquez, F. J., Luque, A., Li, D., MalagónRomero, A., Neubert, T., Chanrion, O., Reglero, V., NavarroGonzalez, J., Lu, G., Zhang, H., Huang, A., \& Østgaard, N. (2020). Blue Optical Observations of Narrow Bipolar Events by ASIM Suggest Corona Streamer Activity in Thunderstorms. Journal of Geophysical Research: Atmospheres, 125(16), [e2020JD032708].

https://doi.org/10.1029/2020JD032708

\section{General rights}

Copyright and moral rights for the publications made accessible in the public portal are retained by the authors and/or other copyright owners and it is a condition of accessing publications that users recognise and abide by the legal requirements associated with these rights.

- Users may download and print one copy of any publication from the public portal for the purpose of private study or research.

- You may not further distribute the material or use it for any profit-making activity or commercial gain

- You may freely distribute the URL identifying the publication in the public portal 


\section{JGR Atmospheres}

\section{RESEARCH ARTICLE \\ 10.1029/2020JD032708 \\ Key Points: \\ - ASIM has detected blue flashes \\ Blue Optical Observations of Narrow Bipolar Events by ASIM Suggest Corona Streamer Activity in Thunderstorms} associated with positive narrow bipolar events; no simultaneous lightning $777.4 \mathrm{~nm}$ emission was recorded

- Source altitudes derived from optical and radio signals agree and locate $\mathrm{NBE}$ and blue flash sources between 8.5 and $14 \mathrm{~km}$ inside the cloud

- Observations suggest that blue flashes are due to streamers, and that positive narrow bipolar events are cloud coronas with many streamers

Correspondence to:

F. J. Gordillo-Vázquez,

vazquez@iaa.es

Citation:

Soler, S., Pérez-Invernón, F. J., Gordillo-Vázquez, F. J., Luque, A.,

Li, D., Malagón-Romero, A., et al. (2020). Blue optical observations of narrow bipolar events by ASIM suggest corona streamer activity in

thunderstorms. Journal of Geophysical

Research: Atmospheres, 125,

e2020JD032708. https://doi.org/

10.1029/2020JD032708

Received 4 MAR 2020

Accepted 13 JUL 2020

Accepted article online 28 JUL 2020

(C)2020. American Geophysical Union. All Rights Reserved.

S. Soler ${ }^{1}$ iD, F. J. Pérez-Invernón ${ }^{1,2}$ iD, F. J. Gordillo-Vázquez ${ }^{1}$ iD, A. Luque ${ }^{1}$ (iD, D. Li ${ }^{1}$ (iD,

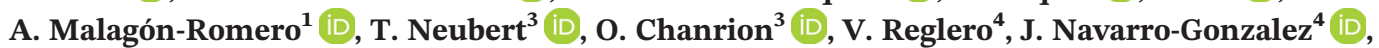

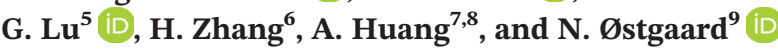

${ }^{1}$ Instituto de Astrofísica de Andalucía, CSIC, Glorieta de la Astronomia s/n, Granada, Spain, ${ }^{2}$ Deutsches Zentrum für Luft- und Raumfahrt, Institut für Physik der Atmosphäre, Oberpfaffenhofen, Germany, ${ }^{3}$ National Space Institute, Technical University of Denmark (DTU Space), Kongens Lyngby, Denmark, ${ }^{4}$ Image Processing Laboratory, University of Valencia, Valencia, Spain, ${ }^{5}$ Key Laboratory of Geospace Environment, Chinese Academy of Sciences, University of Science and Technology of China, Hefei, China, ${ }^{6}$ Key Laboratory for Middle Atmosphere and Global Environment Observation, Institute of Atmospheric Physics, Chinese Academy of Sciences, Beijing, China, ${ }^{7}$ Key Laboratory of Middle Atmosphere and Global Environment Observation (LAGEO), Institute of Atmospheric Physics, Chinese Academy of Sciences, Beijing, China, ${ }^{8}$ Now at Electrical and Computer Engineering Department, Duke University, Durham, NC, USA, ${ }^{9}$ Birkeland Centre for Space Science, Department of Physics and Technology, Bergen, Norway

\begin{abstract}
While narrow bipolar events (NBEs) could be related with lightning initiation, their intrinsic physics remains in question. Here we report on optical measurements by the Atmosphere-Space Interactions Monitor (ASIM) on the International Space Station (ISS) of blue flashes associated with NBEs. They are observed in a narrow blue band centered at $337 \mathrm{~nm}$, with no simultaneous activity at $777.4 \mathrm{~nm}$, considered a strong lightning emission line. From radio waves measured from the ground, we find that 7 of 10 single-pulse blue events can be identified as positive NBEs. The source altitudes estimated from optical and radio signals agree and indicate that the sources of the blue flashes are located between $\sim 8.5$ and $\sim 14 \mathrm{~km}$, in a cloud reaching 14-15 km altitude. The observations suggest that single-pulse blue flashes are from cold ionization waves, so-called streamers, and that positive NBEs are corona discharges formed by many streamers.
\end{abstract}

Plain Language Summary A special type of cloud electrical discharges called narrow bipolar events (NBEs) could be related with lightning initiation, but their intrinsic physics remains in question. Here we report on optical measurements by the Atmosphere-Space Interactions Monitor (ASIM) on the International Space Station (ISS) of blue flashes associated with NBEs. They are observed with no simultaneous optical emissions from regular lightning. From radio waves measured from the ground, we find that $70 \%$ of the detected single-pulse blue events can be identified as positive NBEs. The source altitude estimates from optical and radio signals agree and indicate that the sources of the blue events are located between $\sim 8.5$ and $\sim 14 \mathrm{~km}$ inside the thundercloud. The observations suggest that single-pulse blue flashes are from cold ionization waves, so-called streamers, and that positive NBEs are corona discharges formed by many streamers.

\section{Introduction}

In 1980, Le Vine (1980) first detected strong radio frequency (RF) sources from intracloud (IC) electrical discharge processes characterized by short-duration (10-30 $\mathrm{s}$ ) bipolar sferic waveforms detected in very low frequency $(\mathrm{VLF}) /$ low frequency $(\mathrm{LF})(10-400 \mathrm{kHz})$ radio signals and usually accompanied by strong very high frequency (VHF) (30-300 MHz) radiation bursts, which are called compact intracloud discharges (CIDs) or narrow bipolar events (NBEs) (Smith et al., 1999). Because of the substantial NBE sferic strength, they can be radio detected at hundreds of km distance (Rison et al., 2016). CIDs are also named strong transionospheric pulse pairs (TIPPs), which were originally recorded by the VHF receivers aboard the ALEXIS satellite (Holden et al., 1995). The acronym TIPPs is based purely on the appearance of the VHF pulse recorded on a satellite above the ionosphere containing a distinct double pulse which indicates an elevated intracloud source. TIPPs are not uncommon in-cloud events, being approximately half of all VHF events 
collected by the Fast On-orbit Recording of Transient Events (FORTE) satellite launched in 1997 (Light \& Jacobson, 2002). The impulsive NBE events (or weak TIPPs) seen in the VLF/LF range are still typically 10 times more powerful than the emissions from normal lightning discharges at high frequencies (HF) (3-30 MHz) (Smith et al., 1999). The extensive FORTE VHF recordings distinguished between impulsive events (TIPPs) and nonimpulsive events, the so-called "non-TIPPs" that include both cloud-to-ground (CG) and in-cloud lightning signals such as IC events (Light \& Jacobson, 2002). Fast positive and negative breakdown cause NBEs, and NBEs can initiate normal IC lightning (Rison et al., 2016; Tilles et al., 2019). Recent results suggest that $\sim 10 \%$ of IC lightning discharges are initiated by NBEs, and the rest are triggered by very fast (typically less than $0.5 \mu \mathrm{s}$ ) VHF pulses with no obvious spatial development (Lyu et al., 2019). Note that the terms regular or normal lightning are used hereinafter with the meaning of lightning flashes with durations of a few tens of milliseconds to several seconds with hot leader channels rather than such processes as isolated NBEs which last a few tens of microseconds or the continuous breakdown in overshooting tops.

Jacobson et al. (2013) reported dim optical detections from NBEs by a wideband (0.4-1.1 $\mu \mathrm{m})$ photodiode detector (PDD) sampling at $66 \mathrm{kHz}(15 \mu \mathrm{s})$ on board the FORTE satellite. These dim satellite-based NBE optical recordings produced a peak optical radiance (at $825 \mathrm{~km}$ altitude) above the effective trigger threshold of $350 \mu \mathrm{W} \mathrm{m}{ }^{-2}$ corresponding to $\sim 3 \times 10^{8} \mathrm{~W}$ of peak optical isotropic power at the top of the cloud (Jacobson \& Light, 2012). Because of the wideband (700 nm) filter used, Jacobson et al. (2013) were not able to distinguish the characteristic color of NBE optical emissions. More recently, Chanrion et al. (2017) reported profuse activity of blue electrical discharges at the top of a thunderstorm observed from the International Space Station (ISS).

In this paper, we present the first pure—only $337 \mathrm{~nm}$ (hereafter called blue for simplicity)—pulse-like discharge observations recorded by the Modular Multispectral Imaging Array (MMIA) of the Atmosphere-Space Interactions Monitor (ASIM) aboard the ISS during its flyby over a very active thunderstorm on 14 May 2019 in Indonesia. We first show that the detected in-cloud optical flashes are seen only in the narrowband photometer centered at $337 \mathrm{~nm}$ with peak optical radiances below $25 \mu \mathrm{W} \mathrm{m}{ }^{-2}$, that is, between 14 and 15 times less than the $350 \mu \mathrm{W} \mathrm{m}{ }^{-2}$ effective trigger threshold of the PDD on board the FORTE satellite. We then go on to show VLF/LF radio detections (using a sampling frequency of $1 \mathrm{MHz}$ ) of positive NBEs that occur in coincidence with single-pulse blue optical flashes recorded by ASIM. The source altitudes of NBEs associated with single-pulse blue optical flashes are determined by analysis of ground and sky radio waves (Smith et al., 2004) and by a novel method based on the fitting and analysis of the MMIA optical (photometric) signals. Finally, we conclude that the detected positive NBEs occurring inside thunderclouds are caused by fast (10-30 $\mu$ s) positive breakdown (Rison et al., 2016) accompanied by distinct bluish optical emissions $(337 \mathrm{~nm})$ of corona discharges formed by many streamers with no measurable red (777 nm) light emissions typical of lightning. While double- and multiple-pulse blue flashes detected by MMIA are very briefly discussed in this paper, we focus our discussion, analysis, and conclusions on single-pulse blue flashes.

\section{Observations and Data}

The optical data of blue flashes analyzed here are from the MMIA instrument of ASIM. MMIA incorporates a pair of filtered cameras (operating at $12 \mathrm{fps}$ ), one in the near UV at the strongest spectral line of the $\mathrm{N}_{2}$ SPS $(337 \mathrm{~nm} / 4 \mathrm{~nm})$ and the other camera in one of the strongest lightning emission lines corresponding to neutral oxygen $(777.4 \mathrm{~nm} / 5 \mathrm{~nm})$. The MMIA temporal resolution is provided by three photometers sampling at $100 \mathrm{kHz}$ in the UV at 180-230 nm, capturing part of the nitrogen Lyman-Birge-Hopfield (LBH) band, in the near UV at $337 \mathrm{~nm} / 4 \mathrm{~nm}$ and in the lightning band at $777.4 \mathrm{~nm} / 5 \mathrm{~nm}$ (Chanrion et al., 2019; Neubert et al., 2019). Therefore, MMIA currently offers the highest available spatial ( $\sim 400 \mathrm{~m} /$ pixel), temporal resolution $(100 \mathrm{kHz})$, and optical sensitivity of thunderstorm electrical activity from space. The transient pure blue discharges analyzed in this paper are only detected in the $337 \mathrm{~nm}$ photometer and $337 \mathrm{~nm}$ filtered camera of MMIA with signal at the noise level in the $180-230 \mathrm{~nm}$ photometer and in the lightning (777 $\mathrm{nm})$ camera and photometer.

In order to establish correlations between the blue flashes detected by MMIA, the nearby lightning activity and NBEs, we have used the Vaisala global lightning data set GLD360 (Said \& Murphy, 2016; Said et al., 2010, 2013) and a broadband VLF/LF magnetic sensor composed of two orthogonal induction coils that 
was installed on the campus of University Teknikal Malaysia in Melaka $\left(2.3139^{\circ} \mathrm{N}\right.$ latitude, $102.3185^{\circ} \mathrm{E}$ longitude) since May 2017. The lightning signals were recorded continuously at $1 \mathrm{MHz}$ (with $50 \mathrm{~ns}$ time accuracy) with a detection range of $800 \mathrm{~km}$ (the sensitivity of the VLF/LF sensor decreases gradually with distance from the lightning source). The Melaka VLF/LF station is part of the Chinese Lightning Effects Research Platform (LERP) (Huang et al., 2018; Zhang et al., 2016).

The Vaisala GLD360 global lightning data set is generated by a long-range network that employs both time of arrival (TOA) and magnetic direction finding (MDF) technologies at each sensor to geolocate individual lightning flashes. The sensors, sensitive to the VLF range, use a waveform recognition algorithm to identify specific features in radio atmospherics generated by individual lightning discharges (Said \& Murphy, 2016).

The times of the blue flashes are provided by the MMIA internal clock. The time provided by the GLD360 is assumed to be the correct time of lightning strokes, and other times are adjusted to this. In this regard note that, for the investigated thunderstorm in Indonesia, the MMIA lightning-corrected detection times at the source are found to exhibit a systematic shift of $\Delta t=-28.7 \pm 0.1 \mathrm{~ms}$ with respect to ground-based GLD360 lightning recordings at the source. This time shift is based on the analysis correlating hundreds of $777 \mathrm{~nm}$ optical pulses recorded by MMIA during a time period of $119 \mathrm{~s}$ starting at 13:08:38.54 UTC. The $\Delta t$ is already included in the MMIA times shown in Tables 1 and 2. Finally, the times of the +NBEs are determined by the sferic signals detected by the Melaka VLF/LF radio station.

\section{Observation of Blue Flashes and Lightning}

The blue emissions occurred during a very active thunderstorm on 14 May 2019 over Indonesia. Figure 1shows the cloud top height (CTH) - up to $14-15 \mathrm{~km}$-derived from measurements by the Fengyun-4A (FY-4A) satellite launched on 11 December 2016 and located at $105^{\circ} \mathrm{E}$ longitude observing the Indian Ocean. The CTH retrieved by FY-4A has a vertical resolution of $1 \mathrm{~km}$ (Tan et al., 2019). FY-4A is the first of a new generation of Chinese geostationary meteorological satellites (Yang et al., 2017). FY-4A delivers imagery every $15 \mathrm{~min}$ from the 14 spectral channels of the Advanced Geosynchronous Radiation Imager (AGRI) (Zhang et al., 2018). A repeat cycle of $15 \mathrm{~min}$ for full-disk imaging provides multispectral observations of rapidly changing phenomena like, for instance, deep convection.

A total of 30 blue events of different types (single-, double-, and multiple-pulse) were recorded by MMIA in a relatively short period of time between 13.09.21.4903 and 13.09.54.8739 Coordinated Universal Time (UTC) on 14 May 2019 in a thunderstorm over the island of Sumatra (Indonesia). Figure 1 shows the cloud-toground (CG) lightning activity in the region of interest together with the single-pulse (large squares) and double- and multiple-pulse (small squares) blue flashes forming a cluster and an isolated double-pulse blue event appearing to the upper left of the cluster (see top panel of Figure 1). All blues occur in a region of cloud tops of $\simeq 14-15 \mathrm{~km}$. The blue flashes recorded by MMIA exhibited an occurrence rate of $\sim 48$ per minute (almost one per second).

The short time interval during which blue flashes were detected together with their spatial distribution based on clustering is in agreement with previous findings by Jacobson and Heavner (2005) in connection to the spatial relationship between CGs and NBEs and to the fact that the occurrence of NBEs tends to cover less of the spatial extent or temporal lifetime of the thunderstorm (Jacobson \& Heavner, 2005). We found that there are no neighbor CG lightning discharges in the $10 \mathrm{~ms}$ preceding or following the blue flashes (Jacobson \& Light, 2012). In addition, by looking at Figure 1 one cannot consistently confirm the spatial correlation between blue flashes and CGs. In addition, if we look at Figure 2 we cannot confirm that a sequence of CGs is the cause or the consequence of a blue event. This was also found by Jacobson and Heavner (2005) in the case of NBEs detected during the 4 year (1999-2002) operation of Los Alamos Sferic waveform Array (LASA) in Florida.

Some key features of the 10 single-pulse blues recorded by ASIM are shown in Table 1. The illuminated cloud top area of the blue events ranges between $\sim 24$ and $\sim 131 \mathrm{~km}^{2}$ with a variable number of active pixels between 149 and 819. The number of pixels of the transient blue events are determined by choosing pixels (with an area of $\sim 0.16 \mathrm{~km}^{2}$ ) with a threshold value of $20 \%$ of the maximum and 2 times the minimum pixel value $\left(2 \times 55 \mu \mathrm{W} /\left(\mathrm{m}^{2} \mathrm{sr}\right)\right)$. The total duration time of the photometer signal is obtained from the first-hitting model fit function (see next section) as the time since the fit starts until the value of the fit when it decays to 
Table 1

Narrow and Regular Single-Pulse Blue Flashes Detected by MMIA on Board ASIM

\begin{tabular}{|c|c|c|c|c|c|c|}
\hline $\begin{array}{l}\text { Time (MMIA) } \\
\text { Blue flash } \\
\text { UTC (Source) } \pm 0.1 \mathrm{~ms}\end{array}$ & $\begin{array}{l}\text { Number of } \\
\text { pixels/area } \\
\left(\mathrm{km}^{2}\right)\end{array}$ & $\begin{array}{c}\text { Peak } \\
\text { brightness } \\
\left(\mu \mathrm{W} / \mathrm{m}^{2}\right) /(\mathrm{MR})\end{array}$ & $\begin{array}{c}\text { Total } \\
\text { brightness } \\
\left(\mu \mathrm{Wms} / \mathrm{m}^{2}\right)\end{array}$ & $\begin{array}{l}\text { Rise } \\
\text { time } \\
\text { (ms) }\end{array}$ & $\begin{array}{l}\text { Total } \\
\text { duration } \\
(\mathrm{ms})\end{array}$ & $\begin{array}{c}L \\
\text { (optical) } \\
(\mathrm{km})\end{array}$ \\
\hline $13: 09: 21.4903$ & $243 / 38.9$ & $7.76 / 65.90$ & 7.14 & 0.24 & 2.59 & $2.06-4.13$ \\
\hline 13:09:27.1675 & $442 / 70.7$ & $16.09 / 75.10$ & 16.60 & 0.32 & 2.68 & $2.13-4.25$ \\
\hline $13: 09: 31.8650$ & $488 / 78.1$ & $8.49 / 35.90$ & 8.55 & 0.27 & 2.80 & $2.33-4.66$ \\
\hline 13:09:34.8905 & $819 / 131.0$ & $16.01 / 40.30$ & 12.60 & 0.21 & 2.22 & $1.95-3.90$ \\
\hline 13:09:45.0861 & $196 / 31.4$ & $14.44 / 15.20$ & 8.05 & 0.14 & 1.60 & $1.68-3.37$ \\
\hline 13:09:46.7538 & $504 / 80.6$ & $13.05 / 53.40$ & 16.48 & 0.40 & 3.24 & $2.97-5.95$ \\
\hline $13: 09: 49.4230$ & $149 / 23.8$ & $21.67 / 299.00$ & 19.94 & 0.24 & 2.59 & $2.35-4.70$ \\
\hline 13:09:49.9890 & $210 / 33.6$ & $15.50 / 152.00$ & 20.81 & 0.48 & 3.30 & $3.23-6.45$ \\
\hline 13:09:53.6693 & $161 / 25.8$ & $9.20 / 118.00$ & 7.36 & 0.20 & 2.33 & $2.08-4.17$ \\
\hline 13:09:54.8739 & $435 / 69.6$ & $9.46 / 44.80$ & 13.00 & 0.42 & 3.60 & $2.73-5.46$ \\
\hline
\end{tabular}

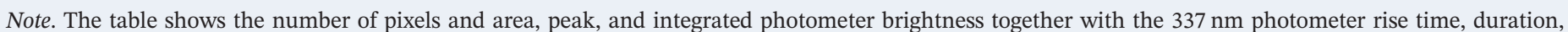

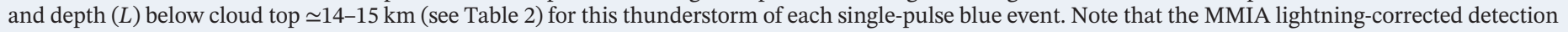

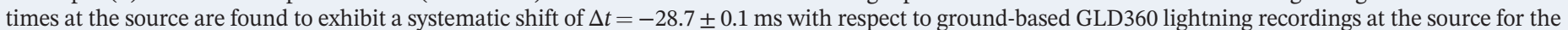

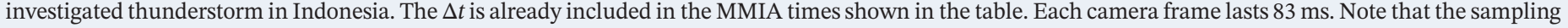

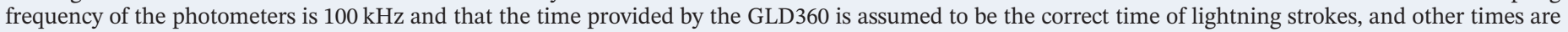
adjusted to this.

$10 \%$ of its maximum value or it is lower than the noise level value $\left(0.5 \mu \mathrm{W} / \mathrm{m}^{2}\right)$. The rise time is the time since the fit function starts until it reaches its maximum. On the other hand, the single blue events rise time, defined as the time up to the maximum, varies between 0.14 and $0.48 \mathrm{~ms}$. The peak brightness as seen by the 337 photometer in $\mu \mathrm{W} / \mathrm{m}^{2}$ varies by a factor of 2.8 (between 7.76 and $21.67 \mu \mathrm{W} / \mathrm{m}^{2}$ ). In the same period of time the peak brightnesses of regular lightning scale from about $1 \mu \mathrm{W} / \mathrm{m}^{2}$ to about $64 \mu \mathrm{W} / \mathrm{m}^{2}$. The cloud-top surface-averaged brightnesses vary between 15.2 and $299 \mathrm{MR}$. Note, however, that for quantifying the peak brightness in Rayleighs we considered the illuminated cloud top area shown by the 337 camera, which will differ from the emitting area of the blue discharge.

The total duration of recorded single blue events varies between 1.60 and $3.60 \mathrm{~ms}$, while the duration of double- and multiple-pulse blue flashes can be of $\simeq 14$ and $\simeq 8 \mathrm{~ms}$, respectively. We have observed that the

Table 2

Times at the Source (Referred to GLD360 Lightning Detections at the Source) of Seven Narrow Single-Pulse Blue Flashes Detected by MMIA and the Associated +NBEs Including the Source Depth Below the Cloud Top L and the Altitude Above Sea Level H Determined by (i) Fitting the Photometer Narrow Single-Pulse (Optical) Blue Flash and by (ii) Analyzing the +NBE Sferic (VLF) Ground and Sky Waves

\begin{tabular}{|c|c|c|c|c|c|c|}
\hline $\begin{array}{l}\text { Time (GLD360) } \\
\text { Lightning } \\
\text { UTC (Source) } \\
\pm 0.1 \mathrm{~ms}\end{array}$ & $\begin{array}{c}\text { Time (MMIA) } \\
\text { Blue flash } \\
\text { UTC (Source) } \\
\pm 0.1 \mathrm{~ms}\end{array}$ & $\begin{array}{c}L \\
\text { (optical) } \\
(\mathrm{km})\end{array}$ & $\begin{array}{l}\text { CTH } \\
(\mathrm{km})\end{array}$ & $\begin{array}{c}\text { Time (VLF) } \\
+ \text { NBE } \\
\text { UTC (Source) } \\
\pm 50 \mathrm{~ns}\end{array}$ & $\begin{array}{c}H \\
\text { (Radio) } \\
(\mathrm{km})\end{array}$ & $\begin{array}{c}d \\
\text { (Radio) } \\
(\mathrm{km})\end{array}$ \\
\hline & 13:09:21.4903 & $2.06-4.13$ & 14 & & & \\
\hline 13:09:27.1676 & $\begin{array}{l}13: 09: 27.1675 \\
13: 09: 31.8650\end{array}$ & $\begin{array}{l}2.13-4.25 \\
2.33-4.66\end{array}$ & $\begin{array}{l}14 \\
15\end{array}$ & 13:09:27.16753743 & 13 & 348 \\
\hline 13:09:34.8905 & 13:09:34.8905 & $1.95-3.90$ & 14 & 13:09:34.89044770 & 12 & 345 \\
\hline $13: 09: 45.0863$ & 13:09:45.0861 & $1.68-3.36$ & 15 & 13:09:45.08622757 & 14 & 351 \\
\hline 13:09:46.7539 & 13:09:46.7538 & $2.97-5.95$ & & 13:09:46.75383847 & 11 & 348 \\
\hline 13:09:49.4232 & $\begin{array}{l}13: 09: 49.4230 \\
13: 09: 49.9890\end{array}$ & $\begin{array}{l}2.35-4.70 \\
3.23-6.45\end{array}$ & 14 & 13:09:49.42311687 & 13 & 354 \\
\hline 13:09:53.6694 & 13:09:53.6693 & $2.09-4.17$ & 14 & 13:09:53.66928803 & 13 & 363 \\
\hline 13:09:54.8740 & 13:09:54.8739 & $2.73-5.46$ & 14 & 13:09:54.87398350 & 11 & 364 \\
\hline
\end{tabular}

Note. The table also shows the specific cloud top height (CTH) in the location of the single-pulse blue flash and the distance $d$ of the events to the Melaka VLF/LF ground-based station derived by radio signal analysis. The times of the blue flashes are provided by the MMIA internal clock. The times of the + NBEs are determined by the Melaka VLF/LF ground-based station. Note that the MMIA lightning-corrected detection times at the source are found to exhibit a systematic $\Delta t=-28.7 \pm 0.1 \mathrm{~ms}$ shift with respect to ground-based GLD360 lightning recordings at the source for the investigated thunderstorm in Indonesia. The $\Delta t$ is already included in the MMIA times shown in the table. The uncertainty in $H$ is $\pm 1 \mathrm{~km}$ (Li et al., 2019, 2020). CTH is the cloud top height derived by the FY-4A geostationary satellite for the position of each ASIM-detected single-pulse blue flash. The CTH has a vertical resolution of $1 \mathrm{~km}$ (Tan et al., 2019). 

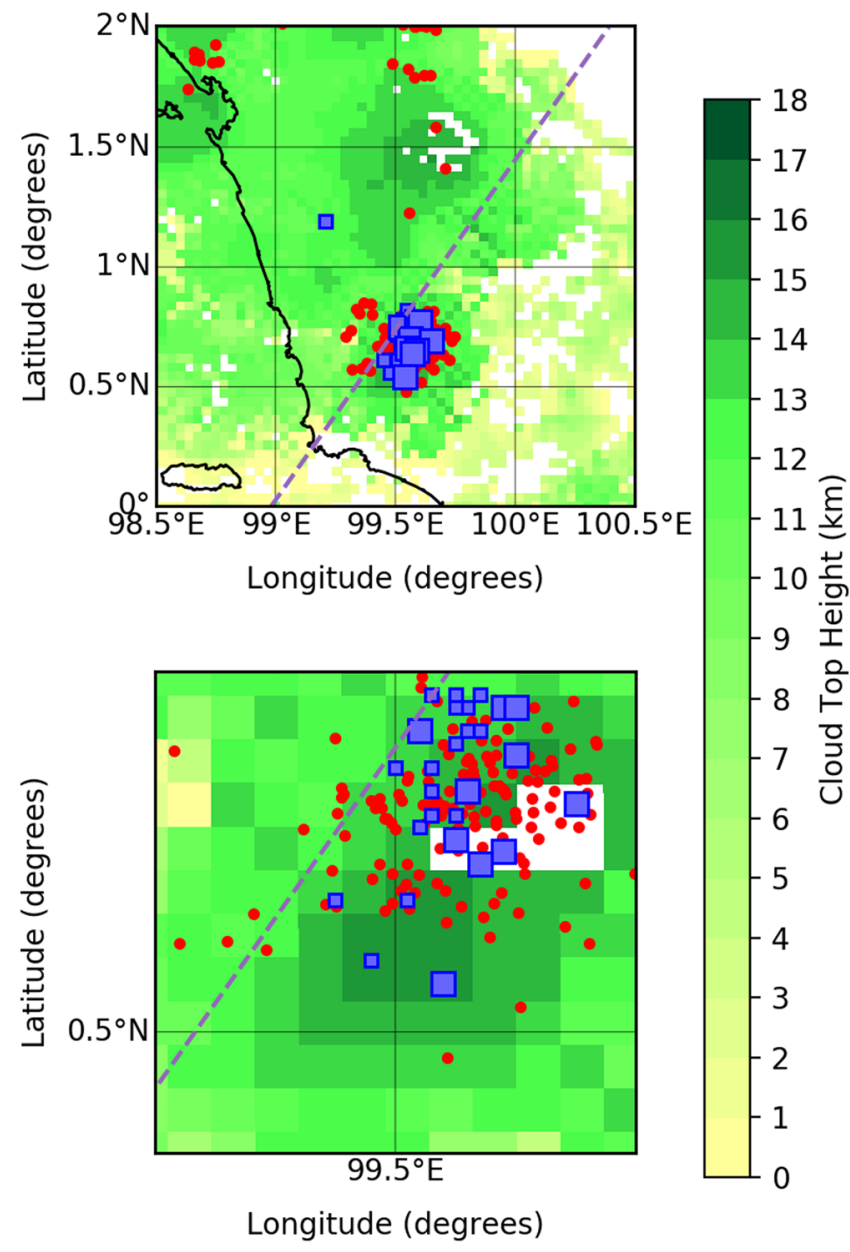

Figure 1. (upper panel) Single- (big blue squares), double-, and multiple-pulse blue events (small blue squares) and cloud to ground (CG) lightning (small red dots) detected between 13:09 and 13:12 UTC by GLD360 represented over a cloud top height (CTH) map derived from ( $4 \mathrm{~km} \times 4 \mathrm{~km}$ spatial resolution) measurements by the Chinese

Fengyun-4A (FY-4A) geostationary meteorological satellite. (bottom panel) Zoom-in of the top panel where more details can be observed.

Thundercloud CTHs between 14 and $15 \mathrm{~km}$ close to the tropopause are visible. The white spots are missing values. The dashed line represents the ISS orbit. typical individual pulse contained in double- and multiple-pulse events lasts longer than the typical isolated pulse, suggesting that doubleand/or multiple-pulse events either have a deeper source or are produced by discharge mechanisms with significantly longer time scales.

There were a total of 1,360 lightning strokes reported by Vaisala GLD360 within a 5 min interval (from 13.07 UTC to 13.12 UTC) in an area (from $-1.6^{\circ}$ latitude, $97^{\circ}$ longitude to $3.4^{\circ}$ latitude, $102^{\circ}$ longitude) of the thunderstorm region within a square of $5^{\circ} \times 5^{\circ}$ around the detected blue events. The ground-based Vaisala GLD360 global lightning network detected 1,360 lightning strokes and classified 359 as CG and 1,001 as IC.

Figure 2 shows a temporal sequence of single-pulse blue events (vertical dashed lines) and the cumulative number of IC (green dots) and CG (red dots) lightning strokes as classified by GLD360 occurring in a square centered in the centroid of the detected blue flashes (see caption of Figure 2 for details). Figure 2 also shows the cumulative number of 777 $\mathrm{nm}$ flashes detected by the MMIA $777 \mathrm{~nm}$ photometer between $5 \mathrm{~s}$ before the first single-pulse blue flash and $5 \mathrm{~s}$ after the last single-pulse blue flash.

As seen in Figure 2, most of the MMIA-detected single blue events do not exhibit a clear predecessor or successor CG with most blue flashes being temporally isolated with respect to $\mathrm{CG}$ strokes. There are two single-pulse blue flashes classified as +NBE at 13:09:46.7538 UTC and 13:09:54.8739 UTC that seem to occur simultaneously (within error; see Table 2) with two CG lightning strokes as classified (possibly misclassified) by GLD360, but no concurrent $777 \mathrm{~nm}$ optical emissions were detected by MMIA.

The seven identified +NBEs (in coincidence with single-pulse blue flashes) occur simultaneously (within error; see Table 2) with five IC and two CG lightning strokes as classified by GLD360. However, no concurrent $777 \mathrm{~nm}$ optical emissions were detected by MMIA in any of the seven cases. Out of these seven +NBEs, only the one occurring at 13:09:34.8905 UTC (fourth vertical dashed line from the left; see Table 2) seems to initiate seven successive IC lightning strokes (out of a total of 79 GLD360-detected IC strokes in this time interval and spatial area (see caption of Figure 2) in agreement with recent results suggesting that $\sim 10 \%$ of IC lightning strokes are initiated by NBEs (Lyu et al., 2019).

As mentioned before from looking at the GLD360 data, there are eight GLD360 strokes (seven classified as IC and one classified [possibly misclassified] as CG) within $15 \mathrm{~km}$ and up to $750 \mathrm{~ms}$ after the fourth blue flash. These strokes probably belonged to an IC flash which was initiated by the positive NBE associated with this fourth blue flash, which means the light emissions from these strokes were probably about the same location in the cloud as the blue flash. Figure 2 indicates that there were $777 \mathrm{~nm}$ emissions detected from these strokes. This suggests that $777 \mathrm{~nm}$ emissions from these strokes were able to get out of the cloud, but no $777 \mathrm{~nm}$ emission from the blue flash was able to get out of the cloud. This has allowed us to put limits on the $777 \mathrm{~nm}$ emissions from the blue flash compared to the other strokes in this flash. We found that the maximum 777 peak intensity in this period was $\simeq 17 \mu \mathrm{W} \mathrm{m}{ }^{-2}$. Considering that the noise level of the red photometer is $\simeq 0.35 \mu \mathrm{W} \mathrm{m}^{-2}$, the 777 peak intensity in the blue event is at least a factor 50 (or 25) below the 777 maximum (or mean) peak emissions of other discharges in the same flash. The factor 25 is derived considering 777 peaks barely above $\left(2 \mu \mathrm{W} \mathrm{m}^{-2}\right)$ the noise. These factors 50 and 25 are in agreement with streamer spectra recorded at $25 \mathrm{mbar}$ in air (equivalent to $\simeq 25 \mathrm{~km}$ altitude) showing that the blue near-ultraviolet optical emissions of the second positive system (SPS) of $\mathrm{N}_{2}$ dominates over a small (almost indistinguishable) trace of the $777.4 \mathrm{~nm}$ line that is less than $1 \%$ of the SPS of $\mathrm{N}_{2}$ (Ebert et al., 2010) as we comment in section 5. 


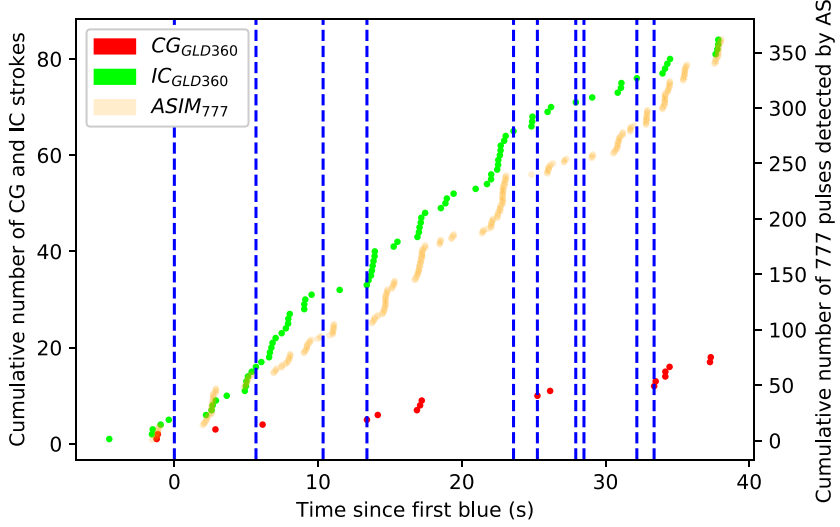

Figure 2. The vertical dashed lines indicate the temporal sequence of single-pulse blue flashes detected by ASIM. The right axis marks the cumulative number of ASIM $777 \mathrm{~nm}$ flashes (orange dots) detected in its field of view between $5 \mathrm{~s}$ before the first single-pulse blue flash and $5 \mathrm{~s}$ after the last single-pulse blue event. The left axis indicates the cumulative number of cloud discharges classified by GLD360 as CG lightning strokes (red dots) and IC lightning strokes (green dots) occurring within a square of $1^{\circ}$ side centered in the centroid of the blue events and counting between $5 \mathrm{~s}$ before the first single-pulse blue flash and $5 \mathrm{~s}$ after the last single-pulse blue event.
There is a continuous CG and IC lightning occurrence in the nearby (several milliseconds) times when single blue flashes are detected by ASIM. This is consistent with the findings by Wu et al. (2011) reporting that \pm NBEs occur in relative temporal isolation with respect to normal lightning discharges.

The detected transient events in this study are purely blue events, that is, there was no detectable $777 \mathrm{~nm}$ optical emissions typical of ordinary lightning. As previously mentioned, the duration of the single-pulse blue optical emissions is between 1.60 and $3.60 \mathrm{~ms}$. Figure 3 shows three representative examples of the types of blue events recorded with ASIM. An example of a single-pulse blue event lasting about $3.5 \mathrm{~ms}$ is shown in the top panel of Figure 3. The middle and bottom panels of Figure 3 illustrate the temporal durations (photometer), shape, and appearance (image) of, respectively, a double- and a multiple-pulse blue event with "long" durations of 14 and $8 \mathrm{~ms}$, respectively. The ASIM photometer signal of a single-pulse blue flash shown in the top panel of Figure 3 is fitted with a distribution function (orange line) resulting from considering the process of scattering and absorption (see next section) experienced by photons traveling through the cloud.

\subsection{Derivation of Altitudes From Photometer Signals}

The temporal profile of optical emissions emanating from deep within a cloud is dominated by the time of multiple photon scattering by cloud droplets and ice crystals (Light et al., 2001; Thomason \& Krider, 1982). Under the assumptions that the optical pulse is impulsive and localized, that the cloud is homogeneous and bounded above by a plane, and that the photons exit the cloud isotropically, with scattering outside the cloud being negligible, one can derive a simple expression for the signal registered by a photometer above the cloud top. As we see below, this expression provides a rough estimate of event altitudes.

If the source is far from the cloud boundary, the photons experience so many scattering events before exiting the cloud that their transport is well approximated by a diffusive process with a diffusion coefficient $D=\Lambda c /$ $\left(3\left(1-g \omega_{0}\right)\right)$ (Koshak et al., 1994), where $\Lambda$ is the photon mean free path, $c$ is the speed of light, $g$ is the scattering assymetry parameter, and $\omega_{0}$ is the single-scattering albedo. Since the radius of the cloud droplets is much larger than the optical wavelengths of interest, one can assume an extinction efficiency of 2 (Hulst, 1981) and express the mean free path as $\Lambda=\left(2 \pi r^{2} n\right)^{-1}$ with $r$ being the radius of scatterers and $n$ their concentration. The single-scattering albedo $\omega_{0}$ denotes the probability that a photon is reemitted after a scattering event, and under our conditions it is close to unity. Nevertheless, over the course of many collisions a photon may accumulate a nonnegligible probability of being absorbed. We express this by means of an absorption rate $\nu_{0}=c\left(1-\omega_{0}\right) / \Lambda$. However, the signal decay is not only determined by absorption in scattering events but also by photons leaving the cloud from the lower and lateral boundaries. Hence, we consider an effective decay rate $\nu$ which is a model parameter derived from the photometer curve.

The time profile of the signal is then determined by the probability distribution of the time that it takes a diffusing and weakly absorbed particle to reach a plane at a distance $L$ from its starting point. In our case $L$ is the distance from the event to the cloud top. This problem belongs to the family of first-passage (or first-hitting-time) problems and can be solved by standard methods of statistical physics (see, e.g., Krapivsky et al., 2010). The solution reads

$$
f(t)=\frac{\theta\left(t-t_{0}\right) e^{2 \sqrt{\nu \tau}}}{\tau \sqrt{\pi}}\left(\frac{\tau}{t-t_{0}}\right)^{3 / 2} e^{-\tau /\left(t-t_{0}\right)-v\left(t-t_{0}\right)}, \text { with } \int_{-\infty}^{\infty} f(t) d t=1
$$

where $\theta$ is the step function, $t_{0}$ is the emission time, and $\tau=L^{2} / 4 D$ is the characteristic time of the process. Given a photometer signal, one can fit it to (1) and obtain values for the parameters $t_{0}, \tau$, and $\nu$. Then the depth of the event can be estimated as $L=(4 D \tau)^{1 / 2} \approx(4 \Lambda c \tau /(3(1-g)))^{1 / 2}$. In this work we used $g=0.87$ (Thomason $\&$ Krider, 1982) and $\Lambda=4$ to $16 \mathrm{~m}$, corresponding to a scatterer concentration $n=10^{8} \mathrm{~m}^{-3}$ and radii $r=10$ to 

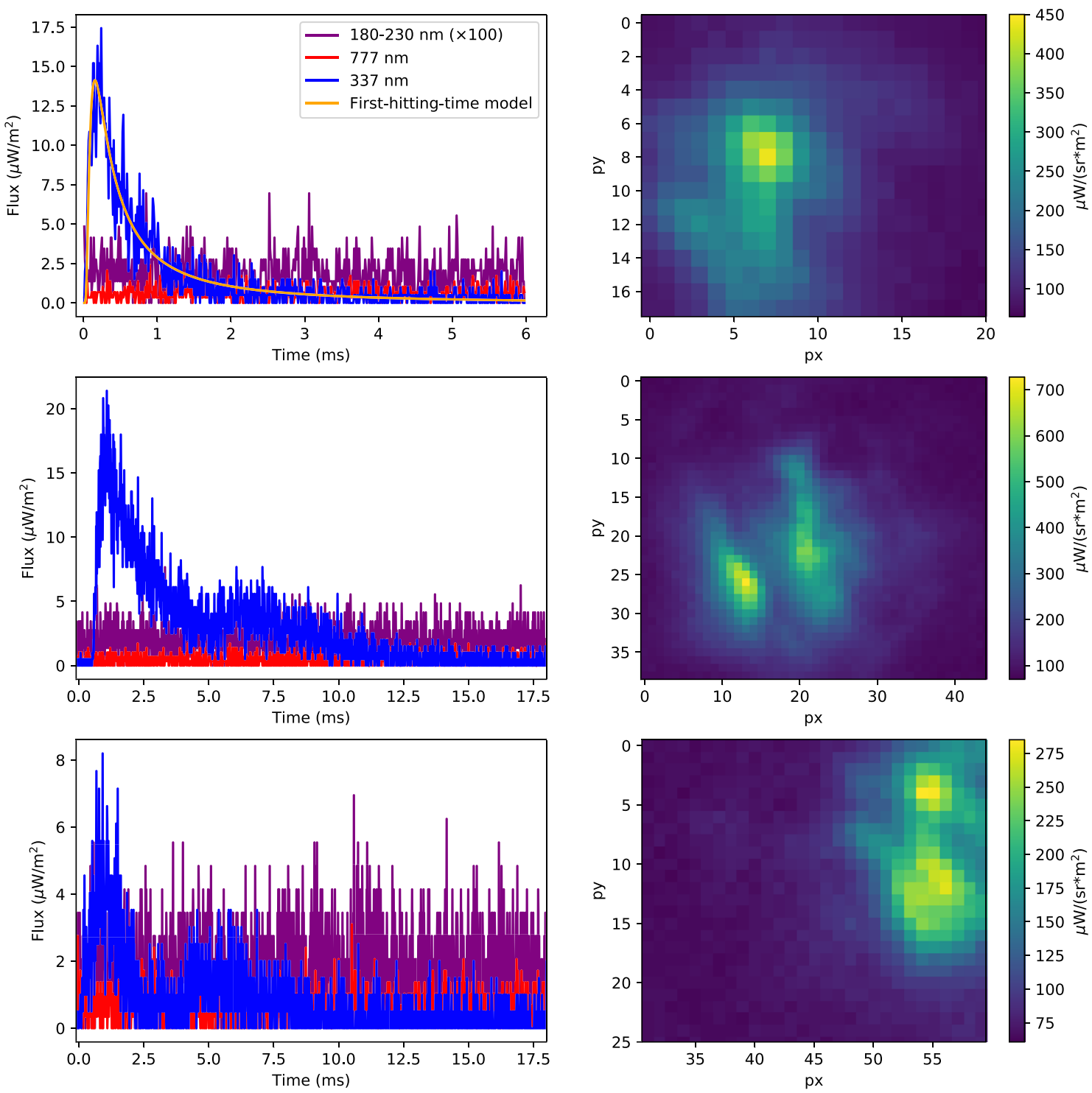

Figure 3. (top panel) Photometer signal (left) and $337 \mathrm{~nm}$ image (right) recorded by MMIA at 13:09:45.0861 UTC (source) corresponding to a narrow single-pulse blue event illuminating a cloud top area of $31.4 \mathrm{~km}^{2}$. The photometric signal (blue line) is well fitted by a distribution accounting for the scattering and absorption of photons in the thundercloud (orange line). Note that the $777.4 \mathrm{~nm}$ signal (red line) typical of lightning is in the noise level. The $180-230 \mathrm{~nm}$ photometric signal is also represented (purple line) with a $\times 100$ factor. (middle and bottom panels) Photometer signals (left) and $337 \mathrm{~nm}$ images (right) recorded by MMIA corresponding to double-pulse (middle panel) and multiple-pulse (bottom panel) blue flashes lasting about 14 and 8 ms, respectively. Signals in the noise level are simultaneously detected in the MMIA $777.4 \mathrm{~nm}$ photometer and camera.

$20 \mu \mathrm{m}$ (Thomason \& Krider, 1982), which correspond to a range of the diffusion coefficient $D$ from $3 \times 10^{9}$ to $12 \times 10^{9} \mathrm{~m}^{2} \mathrm{~s}^{-1}$. The resulting values of $L$ are listed in Tables 1 and 2 . Note that for our purposes the optical properties of water and ice are close enough to ignore their difference.

It is worth mentioning that the distribution shown in Equation 1 could be applied to any type of single-pulse light emission sources inside clouds other than those only emitting in the near ultraviolet $(337 \mathrm{~nm})$. For example, it could be applied to lightning pulses usually recorded in the $777 \mathrm{~nm}$ optical range. This will allow an estimation of the altitude where different lightning sources are located in thunderclouds and a comparison with other procedures like the use of lightning mapping arrays (LMAs), interferometric or VLF techniques. In this study, we compare the relative to cloud top altitudes derived by optical fit with the altitude of associated positive NBEs detected by the Melaka VLF ground-based station (see Table 1). 
The above analytic Equation 1 is consistent with a full scattering model of lightning optical emissions (Luque et al., 2020) that simulates how a satellite observes optical radiation emitted by a lightning flash after it is scattered within an intervening cloud. This model is specifically tailored to modern instruments such as the MMIA component of the ASIM that operates from the ISS but can also be used in a wider context of lightning scattering.

\section{Ground-Based Radio Detection}

For the comparison with VLF detections, we focus our analysis on single-pulse blue flashes. While the time correlation between blue $(337 \mathrm{~nm}$ ) pulses, $777 \mathrm{~nm}$ pulses, and the GLD360 network is weak, the correlation between blue pulses and the Melaka NBE signature is excellent (about $100 \mu \mathrm{s}$ ), as shown in Table 2. Seven of the 10 single-pulse blue flashes detected by ASIM during its flyby over the Indonesian thunderstorm of 14 May 2019 occurred simultaneously to lightning detected by GLD360 and by the Melaka VLF/LF ground-based station. The analysis of the radio atmospheric signals (sferics) of IC lightning revealed that seven of them exhibited the typical fast $(10-30 \mu \mathrm{s})$ bipolar shape of positive NBEs. We consider narrow single pulses having a duration of $\leq 4 \mathrm{~ms}$. We hereafter distinguish between narrow single-pulse blue events likely associated to NBEs and those with no detected NBEs.

Table 2 shows all times at the source (referred to GLD360 lightning detections at the source) of narrow and regular single-pulse blue flashes detected by MMIA and the associated +NBEs including their depths below cloud top (source altitude is determined by substracting depth from cloud top height) determined by (i) fitting the photometer narrow single-pulse (optical) blue flash and by (ii) analyzing the relative times of arrival of +NBE signal reflections (sky waves) from the ionosphere and ground waves with an uncertainty of $\pm 1 \mathrm{~km}$ (Li et al., 2019, 2020). The table also shows the distance $d$ from the events to the Melaka VLF/LF station derived by GLD360 location and the altitude of NBEs that was determined by calculating the time difference between the ground wave and two reflected sky waves in the VLF/LF radio signal (Smith et al., 2004). Note that $d$ is the great-circle distance calculated by using haversine formula (Robusto, 1957) based on the position between the source provided by GLD360 and the VLF sensor.

The optical source altitudes are determined by subtracting the depth below cloud top derived by analysis of MMIA optical signals from the cloud top heights measured by FY-4A. Table 2 shows that the source altitudes derived by both methods (optical and radio) are consistent and point to source locations inside the clouds producing blue $(337 \mathrm{~nm})$ emissions with no traces of near infrared $(777.4 \mathrm{~nm})$ optical emissions typical of lightning.

Figure 4 (top panel) shows a comparison between the blue flash detected by MMIA at 13:09:54.8739 UTC (source) $\pm 0.1 \mathrm{~ms}$ and the VLF sferic waveforms $-B_{r}$ (red line) and $B_{\phi}$ (green line) magnetic field components-associated to the positive NBE detected at 13:09:54.87398350 UTC (source) \pm 50 ns by the Melaka VLF/LF station. The blue flash and the positive NBE appear isolated from any other nearby cloud electrical activity. Details of the optical signal and VLF sferics of this positive NBE can be seen in the three bottom panels of Figure 4 where we show the zoom-in of the top panel region around the sferic of the NBE.

Both the total duration of the single-pulse blue flashes and the cloud-top illuminated area are related with the location (altitude) of the event in the cloud. In general, the larger the total duration and the illuminated area, the deeper in the cloud the events are located. On the contrary, the shorter the total duration, the higher an event is located in the cloud.

\section{Interpretation and Analysis}

Energetic electrons in corona streamers occurring at upper tropospheric pressures can excite molecules, but also, depending on how high the gained energy is, electrons can dissociate and ionize ambient $\mathrm{N}_{2}$ and/or $\mathrm{O}_{2}$ molecules (Adachi et al., 2008; Gordillo-Vázquez et al., 2011, 2012; Hiraki, 2010; Luque \& Ebert, 2009; Luque \& Gordillo-Vázquez, 2011; Parra-Rojas et al., 2013; Pérez-Invernón et al., 2016; Williams et al., 2012).

Blue optical emissions due to, respectively, the Second Positive System (SPS) of $\mathrm{N}_{2}$ and the First Negative System (FNS) of $N_{2}^{+}$are typical of streamers and corona discharges formed by a large collection of streamers. The high reduced electric field (300-600 Td) in the head of streamers (Luque \& Ebert, 2010; Pasko et al., 1998; Stenbaek-Nielsen et al., 2010) acting during short times-from some nanoseconds (at ground pressure) 

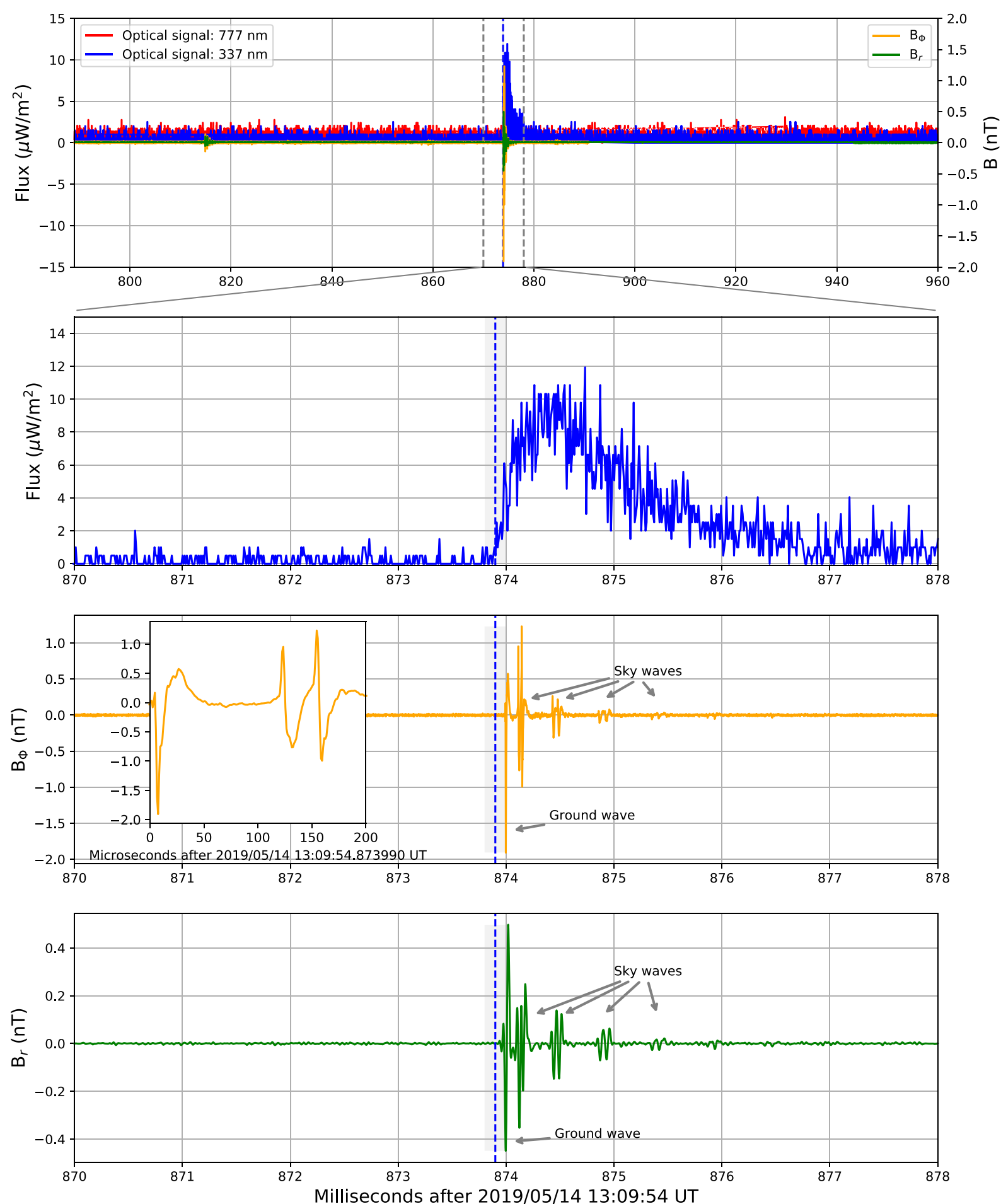

Figure 4. (top panel) Comparison between the narrow single-pulse blue flash (blue line) detected by MMIA at 13:09:54.8739 UTC (source) \pm 0.1 ms (shadowed region in the three bottom panels) and the VLF sferic waveforms $-B_{r}$ (green line) and $B_{\phi}$ (orange line) magnetic field components-associated to the positive NBE detected at 13:09:54.87398350 UTC (source) $\pm 50 \mathrm{~ns}$ by the Melaka VLF/LF station. Note that the $777 \mathrm{~nm}$ optical signal is at the noise level. Details of the optical signal and VLF sferics of this positive NBE can be seen in the three bottom panels, which show the zoom-in of the top panel region around the sferic of the positive NBE. The inset in the $B_{\phi}$ panel shows the $\mu$ s time scale of the detected + NBE. The bipolar waveform of the + NBE ground wave lasts for about $25 \mu \mathrm{s}$. 
to some milliseconds (at mesospheric pressure) — and the short (approximately milliseconds) glow that follows after the propagation of streamer heads can activate nonequilibrium electron-driven kinetics in the surrounding air (Gordillo-Vázquez, 2008; Gordillo-Vázquez \& Donkó, 2009; Hoder et al., 2016; Parra-Rojas et al., 2015; Pérez-Invernón et al., 2018; Sentman et al., 2008). In particular, the production of the ${ }^{5} \mathrm{P}$ electronic state of $\mathrm{O} I$, whose radiative decay produces the $777.4 \mathrm{~nm}$ line, can be activated by (i) electron impact dissociative excitation of $\mathrm{O}_{2}\left(e+\mathrm{O}_{2} \rightarrow \mathrm{O}+\mathrm{O}\left({ }^{5} \mathrm{P}\right)+e\right)$ generating ground state $\mathrm{O}$ I atoms and electronically excited $\mathrm{O}\left({ }^{5} \mathrm{P}\right)$ atoms in a nonequilibrium air plasma and (ii) direct electron impact excitation of ground state of ambient $\mathrm{O}$ I atoms producing electronically excited $\mathrm{O}\left({ }^{5} \mathrm{P}\right)$ atoms $\left(e+\mathrm{O} \rightarrow \mathrm{O}\left({ }^{5} \mathrm{P}\right)+e\right)$. The rate coefficients of mechanisms (i) and (ii) in air increase as the reduced electric field grows, but the production of $\mathrm{O}\left({ }^{5} \mathrm{P}\right)$ by dissociative excitation is always significantly higher than the one by direct electron impact excitation from ground state oxygen atoms. Therefore, depending on the ambient pressure, it could be possible that $777.4 \mathrm{~nm}$ optical emissions appear in well-resolved spectra of streamers. In this regard, it is worth mentioning that the recorded high-resolution spectra of sprites at $74 \mathrm{~km}$ altitude $(\sim 0.023 \mathrm{mbar})$ only show spectroscopic features of neutral molecular nitrogen (Gordillo-Vázquez et al., 2018) with no traces of the strong $777.4 \mathrm{~nm}$ atomic oxygen (O I) triplet usually seen in lightning spectra in the troposphere. However, while streamer spectra recorded at $25 \mathrm{mbar}$ in air (equivalent to $\simeq 25 \mathrm{~km}$ altitude) is dominated by the blue emissions of the SPS of $\mathrm{N}_{2}$, it exhibits a small (almost indistinguishable) trace of the $777.4 \mathrm{~nm}$ line that is less than $1 \%$ of the SPS of $\mathrm{N}_{2}$ (Ebert et al., 2010).

Streamers can appear in isolated corona discharges but also in the forefront of downward or upward propagating hot lightning leaders. Optical emissions of streamers in front of leaders should be accompanied by $777.4 \mathrm{~nm}$ emissions originated by thermal excitation of the ${ }^{5} \mathrm{P}$ electronic state of atomic oxygen in hot lightning channels. However, the single-pulse blue events reported in this paper lack a companion $777.4 \mathrm{~nm}$ emission. This could be due to (i) events occurring deep in the cloud so that accompanying 777.4 $\mathrm{nm}$ optical emissions from streamers and/or leaders are completely absorbed by cloud water droplets and/or ice since both water and ice absorbtion is stronger in the near infrared $(777.4 \mathrm{~nm})$ than in the near ultraviolet (337 nm) (Hale \& Querry, 1973; Warren \& Brandt, 2008), (ii) the presence of low-temperature $(2000-4000 \mathrm{~K})$ leader channels that produce inefficient thermal excitation of $\mathrm{O}\left({ }^{5} \mathrm{P}\right)$ that, consequently, produce negligible $777.4 \mathrm{~nm}$ emissions in comparison with prevailing blue emissions from corona streamers, and/or (iii) the fact that the only source of the detected near-ultraviolet ( $337 \mathrm{~nm}$ ) optical emissions is a corona of many streamers inside the cloud and that, consequently, the $777.4 \mathrm{~nm}$ optical emissions are negligible.

Moreover, as shown in Figure 2 the NBE at 13:09:34.8905 apparently initiated seven IC strokes detected by GLD360. These strokes are almost certainly associated with hot leaders at about the same altitude as this + NBE. It is clear from Figure 2 that the cloud did not absorb the $777 \mathrm{~nm}$ emissions from these strokes since they were detected by MMIA. This strengthens the argument that there is little if any $777 \mathrm{~nm}$ emissions from the short-duration blue flashes. On the other hand, there is no evidence of low-temperature leaders channels which do not produce $777.4 \mathrm{~nm}$ optical emissions.

Having said the above, the fact that no 777.4 photometric signals are simultaneously detected with the recorded blue $(337 \mathrm{~nm})$ signal—or that the 337 and $777 \mathrm{~nm}$ cameras of MMIA show spatially separated structures-together with the derived altitudes of the discharge sources in the thunderclouds leads us to think that the recorded single-pulse blue events are the optical manifestation of corona discharges like positive NBEs occurring at different depths inside thunderclouds in the $8.5-14 \mathrm{~km}$ range between the midlevel main negative and upper positive charge regions of thunderclouds (Bandara et al., 2019; Rison et al., 2016; Smith et al., 2004; Wu et al., 2011). Negative NBEs can occur at higher altitudes (16-20 km), between the upper positive charge cloud layer and the negative screening charge layer above the cloud where normal lightnings rarely occur (Smith et al., 2004; Wu et al., 2011), and might be connected to emerged blue starters (Chou et al., 2018; Liu et al., 2018) in regions with active deep convection.

\section{Conclusions}

The findings of this study are the following:

1. A succession of up to 30 blue flashes forming a cluster during about $33 \mathrm{~s}$ (almost one flash per second) were recorded by the $337 \mathrm{~nm}$ filtered camera and photometer of the MMIA instrument on board 
ASIM. The detected blue events exhibit one, two, or multiple optical pulses (as seen from photometric signals) lasting 1.60-3.60 ms (single) and beyond 14 and $8 \mathrm{~ms}$ (double, multiple).

2. The seven identified +NBEs (in coincidence with single-pulse blue flashes) occur simultaneously (within error, see Table 2) with five ICs and two CGs lightning as classified by GLD360. However, no concurrent $777 \mathrm{~nm}$ optical emissions were detected by MMIA in any of the seven cases. Out of these seven +NBEs, the one occurring at 13:09:34.8905 UTC (fourth blue dashed line from the left, see Figure 2) precedes seven successive IC lightning strokes (out of a total of 79 strokes detected by GLD360 in the area of study), probably initiating a seven-stroke lightning flash in agreement with recent results suggesting that $10 \%$ of IC lightning flashes are initiated by NBEs.

3. None of the recorded (single-, double-, or multiple-pulse) blue flashes exhibit concurrent near infrared $(777.4 \mathrm{~nm})$ optical emissions typical of ordinary lightning. It was found that the 777 peak intensity in the single-pulse blue events is at least a factor 50 (or 25) below the 777 maximum (or mean) peak emissions of other discharges in the same flash.

4. A new method based on the fitting of single blue optical flashes detected by ASIM has allowed us to estimate the depth below cloud top of the events occurring inside thunderstorm clouds. The optically derived event altitudes—ranging between $\sim 1.7$ and $\sim 6.5 \mathrm{~km}$ below a CTH of $\sim 14-15 \mathrm{~km}$ as recorded by the FY-4A satellite-are found to be consistent with heights $(11-14 \mathrm{~km})$ resulting from the analysis of VLF/LF signals of concurrent positive NBEs detected by ground-based VLF stations. The method devel-

\section{Acknowledgments}

This work was supported by the Spanish Ministry of Science and Innovation, Ministerio de Ciencia e Innovación (AEI) under projects ESP2017-86263-C4-4-R and PID2019109269RB-C43 and the FEDER program. S. S. acknowledges a PhD research contract through the project ESP2017-86263-C4-4-R. F. J. P. I., A. L., D. L., and A. M. were supported by the European Research Council (ERC) under the European Union H2020 programme/ERC Grant Agreement 681257. Authors S. S., F. J. P. I., F. J. G. V., A. M., and A. L. acknowledge financial support from the State Agency for Research of the Spanish MCIU through the "Center of Excellence Severo Ochoa" award for the Instituto de Astrofísica de Andalucía (SEV-20170709). ASIM is a mission of The European Space Agency (ESA). The project is funded by ESA and by national grants of Denmark, Norway, and Spain. We acknowledge VAISALA for the granted access to the GLD360 global lightning data set of great value for this work. The authors would like to thank Jiang Lingfeng of the National Satellite Meteorological Center, China Meteorological Administration, who helped preprocess related CTH data based on the data sharing proxy in Fengyun Satellite data center at https:// bit.ly/2ZxNYUT. The authors would like to thank Mohd Riduan Ahamd of the Atmospheric and Lightning Research Lab, Centre for Telecommunication Research and Innovation (CeTRI), Fakulti Kejuruteraan Elektronik dan Kejuruteraan Komputer, Universiti Teknikal Malaysia Melaka, Hang Tuah 7 Jaya, 76100 Durian Tunggal, Melaka, Malaysia. FJPI acknowledges the sponsorship provided by the Federal Ministry for Education and Research of Germany through the Alexander von Humboldt Foundation. oped here is generally valid for single optical pulses (no matter the color) associated to events occurring inside (or almost) the clouds so that photons are affected by scattering and absorption in the cloud.

5. The consistent source altitudes derived by optical and radio signal analysis indicate that the detected single blue flashes are due to optical emissions of streamers occurring in corona discharges forming positive NBEs as suggested from simultaneous (within error) VLF/LF sferics detected by ground-based stations. Double- and multiple-pulse blue flashes might also be due to deep in the cloud pure (with no lightning leader) cloud coronas or lightning leaders and corona streamers with the $777.4 \mathrm{~nm}$ optical emission being absorbed in its way to the detector through the cloud water droplets and ice.

\section{Data Availability Statement}

The data that support the findings of this study are available through figshare repository (at https://figshare. com/s/5ed963f0315dfe04f6b1).

\section{References}

Adachi, T., Hiraki, Y., Yamamoto, K., Takahashi, Y., Fukunishi, H., Hsu, R.-R., et al. (2008). Electric fields and electron energies in sprites and temporal evolutions of lightning charge moment. Journal of Physics D, 41(23), 234010.

Bandara, S., Marshall, T., Karunarathne, S., Karunarathne, N., Siedlecki, R., \& Stolzenburg, M. (2019). Characterizing three types of negative narrow bipolar events in thunderstorms. Atmospheric Research, 227, 263-279.

Chanrion, O., Neubert, T., Mogensen, A., Yair, Y., Stendel, M., Singh, R., \& Siingh, D. (2017). Profuse activity of blue electrical discharges at the tops of thunderstorms. Geophysical Research Letters, 44, 496-503. https://doi.org/10.1002/2016GL071311

Chanrion, O., Neubert, T., Rasmussen, I. L., Stoltze, C., Tcherniak, D., Jessen, N. C., et al. (2019). The Modular Multispectral Imaging Array (MMIA) of the ASIM payload on the International Space Station. Space Science Reviews, 215(4), 28.

Chou, J.-K., Hsu, R.-R., Su, H.-T., Chen, A. B.-C., Kuo, C.-L., Huang, S.-M., et al. (2018). ISUAL-observed blue luminous events: The associated sferics. Journal of Geophysical Research: Space Physics, 123, 3063-3077. https://doi.org/10.1002/2017JA024793

Ebert, U., Nijdam, S., Li, C., Luque, A., Briels, T., \& van Veldhuizen, E. (2010). Review of recent results on streamer discharges and discussion of their relevance for sprites and lightning. Journal of Geophysical Research, 115, A00E43. https://doi.org/10.1029/2009JA014867 Gordillo-Vázquez, F. J. (2008). Air plasma kinetics under the influence of sprites. Journal of Physics D, 41(23), 234016.

Gordillo-Vázquez, F. J., \& Donkó, Z. (2009). Electron energy distribution functions and transport coefficients relevant for air plasmas in the troposphere: Impact of humidity and gas temperature. Plasma Sources Science and Technology, 18(3), 034021.

Gordillo-Vázquez, F. J., Luque, A., \& Simek, M. (2011). Spectrum of sprite halos. Journal of Geophysical Research, 116, A09319. https://doi. org/10.1029/2011JA016652

Gordillo-Vázquez, F. J., Luque, A., \& Simek, M. (2012). Near infrared and ultraviolet spectra of TLEs. Journal of Geophysical Research, 117, A05329. https://doi.org/10.1029/2012JA017516

Gordillo-Vázquez, F. J., Passas, M., Luque, A., Sánchez, J., Velde, O., \& Montanyá, J. (2018). High spectral resolution spectroscopy of sprites: A natural probe of the mesosphere. Journal of Geophysical Research: Atmospheres, 123, 2336-2346. https://doi.org/10.1002/ 2017JD028126

Hale, G. M., \& Querry, M. R. (1973). Optical constants of water in the 200-nm to 200-micrometer wavelength region. Applied Optics, 12(3), 555.

Hiraki, Y. (2010). The phase transition theory of sprite halo. Journal of Geophysical Research, 115, A00E20. https://doi.org/10.1029/ 2009JA014384

Hoder, T., Šimek, M., Bonaventura, Z., Prukner, V., \& Gordillo-Vázquez, F. J. (2016). Radially and temporally resolved electric field of positive streamers in air and modelling of the induced plasma chemistry. Plasma Sources Science and Technology, 25(4), 045021. 
Holden, D., Munson, C., \& Devenport, J. (1995). Satellite observations of transionospheric pulse pairs. Geophysical Research Letters, 22(8), 889-892.

Huang, A., Lu, G., Zhang, H., Liu, F., Fan, Y., Zhu, B., et al. (2018). Locating parent lightning strokes of sprites observed over a mesoscale convective system in Shandong Province, China. Advances in Atmospheric Sciences, 35(11), 1396-1414.

Jacobson, A. R., \& Heavner, M. J. (2005). Comparison of narrow bipolar events with ordinary lightning as proxies for severe convection. Monthly Weather Review, 133, 1144.

Jacobson, A., \& Light, T. (2012). Revisiting“ narrow bipolar event” intracloud lightning using the FORTE satellite. Annales Geophysicae, $30,389$.

Jacobson, A., Light, T., Hamlin, T., \& Nemzek, R. (2013). Joint radio and optical observations of the most radio-powerful intracloud lightning discharges. Annales Geophysicae, 31, 563-580.

Koshak, W. J., Solakiewicz, R. J., Phanord, D. D., \& Blakeslee, R. J. (1994). Diffusion model for lightning radiative transfer. Journal of Geophysical Research, 99(D7), 14,361-14,371.

Krapivsky, P., Redner, S., \& Ben-Naim, E. (2010). A kinetic view of statistical physics. New York: Cambridge University Press.

Le Vine, D. M. (1980). Sources of the strongest RF radiation from lightning. Journal of Geophysical Research, 85(C7), 4091-4095.

Li, D., Liu, F., Luque, A., \& Lu, G. (2019). The propagation effect of NBES by using FDTD model and compare with ground-based measurements at different distances. In AGU fall meeting 2019. San Francisco: American Geophysical Union.

Li, D., Liu, F., Pérez-Invernón, F., Lu, G., Qin, Z., Zhu, B., \& Luque, A. (2020). On the accuracy of ray-theory methods to determine the altitudes of intra-cloud electric discharges and ionospheric reflections: Application to narrow bipolar events. Journal of Geophysical Research: Atmospheres, 125, e2019JD032099. https://doi.org/10.1029/2019JD032099

Light, T., \& Jacobson, A. (2002). Characteristics of impulsive VHF lightning signals observed by the FORTE satellite. Journal of Geophysical Research, 107(D24), 4756. https://doi.org/10.1029/2001JD001585

Light, T. E., Suszcynsky, D. M., Kirkland, M. W., \& Jacobson, A. R. (2001). Simulations of lightning optical waveforms as seen through clouds by satellites. Journal of Geophysical Research, 106(D7), 17,103-17,114. https://doi.org/10.1029/2001JD900051

Liu, F., Zhu, B., Lu, G., Qin, Z., Lei, J., Peng, K.-M., et al. (2018). Observations of blue discharges associated with negative narrow bipolar events in active deep convection. Geophysical Research Letters, 45, 2842-2851. https://doi.org/10.1002/2017GL076207

Luque, A., \& Ebert, U. (2009). Emergence of sprite streamers from screening-ionization waves in the lower ionosphere. Nature Geoscience, $2,757$.

Luque, A., \& Ebert, U. (2010). Sprites in varying air density: Charge conservation, glowing negative trails and changing velocity. Geophysical Research Letters, 37, L06806. https://doi.org/10.1029/2009GL041982

Luque, A., \& Gordillo-Vázquez, F. J. (2011). Modeling and analysis of $\mathrm{N}_{2}\left(\mathrm{~B}^{3} \Pi_{g}\right)$ and $\mathrm{N}_{2}\left(\mathrm{C}^{3} \Pi_{u}\right)$ vibrational distributions in sprites. Journal of Geophysical Research, 116, A02306. https://doi.org/10.1029/2010JA015952

Luque, A., Gordillo-Vázquez, F. J., Li, D., Malagón-Romero, A., Pérez-Invernón, F. J., Schmalzried, A., et al. (2020). Modeling lightning observations from space-based platforms (CloudScat. jl 1.0). Geoscientific Model Development Discussions, $13,1-26$.

Lyu, F., Cummer, S. A., Qin, Z., \& Chen, M. (2019). Lightning initiation processes imaged with very high frequency broadband interferometry. Journal of Geophysical Research: Atmospheres, 124, 2994-3004. https://doi.org/10.1029/2018JD029817

Neubert, T., Østgaard, N., Reglero, V., Blanc, E., Chanrion, O., Oxborrow, C. A., et al. (2019). The ASIM mission on the International Space Station. Space Science Reviews, 215(2), 26.

Parra-Rojas, F. C., Luque, A., \& Gordillo-Vázquez, F. J. (2013). Chemical and electrical impact of lightning on the Earth mesosphere: The case of sprite halos. Journal of Geophysical Research: Space Physics, 118, 5190-5214. https://doi.org/10.1002/jgra.50449

Parra-Rojas, F. C., Luque, A., \& Gordillo-Vázquez, F. J. (2015). Chemical and thermal impact of sprite streamers in the Earth's mesosphere. Journal of Geophysical Research: Space Physics, 120, 8899-8933. https://doi.org/10.1002/2014JA020933

Parra-Rojas, F. C., Passas, M., Carrasco, E., Luque, A., Tanarro, I., Simek, M., \& Gordillo-Vázquez, F. J. (2013). Spectroscopic diagnosis of laboratory air plasmas as a benchmark for spectral diagnosis of TLEs. Journal of Geophysical Research: Space Physics, 118, 4649-4661. https://doi.org/10.1002/jgra.50433

Pasko, V. P., Inan, U. S., \& Bell, T. F. (1998). Spatial structure of sprites. Geophysical Research Letters, $25,2123$.

Pérez-Invernón, F. J., Gordillo-Vázquez, F. J., \& Luque, A. (2016). On the electrostatic field created at ground level by a halo. Geophysical Research Letters, 43, 7215-7222. https://doi.org/10.1002/2016GL069590

Pérez-Invernón, F. J., Luque, A., \& Gordillo-Vázquez, F. J. (2018). Modeling the chemical impact and the optical emissions produced by lightning-induced electromagnetic fields in the upper atmosphere: The case of halos and elves triggered by different lightning discharges. Journal of Geophysical Research: Atmosphere, 123, 7615-7641. https://doi.org/10.1029/2017JD028235

Rison, W., Krehbiel, P. R., Stock, M. G., Edens, H. E., Shao, X.-M., Thomas, R. J., et al. (2016). Observations of narrow bipolar events reveal how lightning is initiated in thunderstorms. Nature communications, 7, 10721.

Robusto, C. C. (1957). The cosine-haversine formula. The American Mathematical Monthly, 64(1), 38-40.

Said, R., Cohen, M., \& Inan, U. (2013). Highly intense lightning over the oceans: Estimated peak currents from global GLD360 observations. Journal of Geophysical Research: Atmospheres, 118, 6905-6915. https://doi.org/10.1002/jgrd.50508

Said, R., Inan, U., \& Cummins, K. (2010). Long-range lightning geolocation using a VLF radio atmospheric waveform bank. Journal of Geophysical Research, 115, D23108. https://doi.org/10.1029/2010JD013863

Said, R., \& Murphy, M. (2016). GLD360 upgrade: Performance analysis and applications. In 24th International Lightning Detection Conference. San Diego, CA: International Lightning Detection Conference and International Lightning Meteorology Conference.

Sentman, D. D., Stenbaek-Nielsen, H. C., McHarg, M. G., \& Morrill, J. S. (2008). Plasma chemistry of sprite streamers. Journal of Geophysical Research, 113, D11112. https://doi.org/10.1029/2007JD008941

Smith, D., Heavner, M., Jacobson, A., Shao, X., Massey, R., Sheldon, R., \& Wiens, K. C. (2004). A method for determining intracloud lightning and ionospheric heights from VLF/LF electric field records. Radio Science, 39, RS1010. https://doi.org/10.1029/2002RS002790

Smith, D., Shao, X., Holden, D., Rhodes, C., Brook, M., Krehbiel, P., et al. (1999). A distinct class of isolated intracloud lightning discharges and their associated radio emissions. Journal of Geophysical Research, 104(D4), 4189-4212.

Stenbaek-Nielsen, H. C., Haaland, R., McHarg, M. G., Hensley, B. A., \& Kanmae, T. (2010). Sprite initiation altitude measured by triangulation. Journal of Geophysical Research, 115, A00E12. https://doi.org/10.1029/2009JA014543

Tan, Z., Ma, S., Zhao, X., Yan, W., \& Lu, W. (2019). Evaluation of cloud top height retrievals from China's next-generation geostationary meteorological satellite FY-4A. Journal of Meteorological Research, 33(3), 553-562.

Thomason, L. W., \& Krider, E. P. (1982). The effects of clouds on the light produced by lightning. Journal of Atmospheric Sciences, 39, 2051. van der Hulst, H. (1981). Light scattering by small particles: Dover Publications. 
Tilles, J. N., Liu, N., Stanley, M. A., Krehbiel, P. R., Rison, W., Stock, M. G., et al. (2019). Fast negative breakdown in thunderstorms. Nature Communications, 10(1), 1648

Warren, S. G., \& Brandt, R. E. (2008). Optical constants of ice from the ultraviolet to the microwave: A revised compilation. Journal of Geophysical Research, 113, D14220. https://doi.org/10.1029/2007JD009744

Williams, E., Kuo, C. L., Bór, J., Sátori, G., Newsome, R. T., Adachi, R., et al. (2012). Resolution of the sprite polarity paradox: The role of halos. Radio Science, 47, RS2002. https://doi.org/10.1029/2011rs004794

Wu, T., Dong, W., Zhang, Y., \& Wang, T. (2011). Comparison of positive and negative compact intracloud discharges. Journal of Geophysical Research, 116, D03111. https://doi.org/10.1029/2010JD015233

Yang, J., Zhang, Z., Wei, C., Lu, F., \& Guo, Q. (2017). Introducing the new generation of Chinese geostationary weather satellites, Fengyun4. Bulletin of the American Meteorological Society, 98(8), 1637-1658.

Zhang, H., Lu, G., Qie, X., Jiang, R., Fan, Y., Tian, Y., et al. (2016). Locating narrow bipolar events with single-station measurement of low-frequency magnetic fields. Journal of Atmospheric and Solar-Terrestrial Physics, 143, 88-101.

Zhang, P., Zhu, L., Tang, S., Gao, L., Chen, L., Zheng, W., et al. (2018). General comparison of FY-4A/AGRI with other GEO/LEO instruments and its potential and challenges on non-meteorological applications. Frontiers in Earth Science, 6, 224 